\title{
Some Aspects of Fluctuating Vertical Wind Shears
}

\author{
J. C. Doran
}

May 1981

Prepared for the U.S. Department of Energy under Contract DE-AC06-76RLO 1830

Pacific Northwest Laboratory Operated for the U.S. Department of Energy by Battelle Memorial Institute 


\title{
NOTICE
}

This report was prepared as an account of work sponsored by the United States Government. Neither the United States nor the Department of Energy, nor any of their employees, nor any of their contractors, subcontractors, or their employees, makes any warranty, express or implied, or assumes any legal liability or responsibility for the accuracy, completeness or usefulness of any information, apparatus, product or process disclosed, or represents that its use would not infringe privately owned rights.

The views, opinions and conclusions contained in this report are those of the contractor and do not necessarily represent those of the United States Government or the United States Department of Energy.

\author{
PACIFIC NORTHWEST LABORATORY \\ operated by \\ BATTELLE \\ for the \\ UNITED STATES DEPARTMENT OF ENERGY \\ Under Contract DE-AC06-76RLO 1830
}

\author{
Printed in the United States of America \\ Available from \\ National Technical Information Service \\ United States Department of Commerce \\ 5285 Port Royal Road \\ Springfieid, Virginia 22151
}

Price: Printed Copy $\$$ $\because$ Microfiche $\$ 3.00$

-Pages Selling Price

$\begin{array}{rr}001-025 & \$ 4.00 \\ 026-050 & \$ 4.50 \\ 051-075 & \$ 5.25 \\ 076-100 & \$ 6.00 \\ 101-125 & \$ 6.50 \\ 126-150 & \$ 7.25 \\ 151-175 & \$ 8.00 \\ 176-200 & \$ 9.00 \\ 201-225 & \$ 9.25 \\ 226-250 & \$ 9.50 \\ 251-275 & \$ 10.75 \\ 276-300 & \$ 11.00\end{array}$


J. C. Doran

May 1981

Prepared for

the U.S. Department of Energy under Contract DE-AC06-76RLO 1830

Pacific Northwest Laboratory Richland, Washington 99352 
, 


\section{SUMMARY}

Fluctuating vertical shears of wind speed have been measured using an array of towers. The statistical distributions of these shears are compared with formulas proposed by Fichtl $(1971,1972)$ and good agreement is found. A comparison of Fichtl's formula for $\sigma_{\Delta u}$, the standard deviation of the fluctuating shears, with a more empirical one proposed by Ramsdel1 (1978) shows that the latter is consistent with the former under the proper conditions.

$\sigma_{\Delta u}$ is also shown to be strongly affected by $\tau$, the averaging time used for the shear measurements. Increasing $\tau$ from 0.2 seconds to 4 seconds can decrease $\sigma_{\Delta u}$ by $25 \%$ or more; the precise amount seems to depend on the vertical separation of the two measuring points.

The probability of occurrence of extreme shears in speed is discussed. Directional shears are not treated here. Fluctuating shears two or more times larger than the mean values are shown to be readily obtainable, and their likelihood increases as the mean measuring height increases if $\Delta z$ is held fixed. These results are applicable for slightly unstable to neutral conditions over level, homogeneous terrain, and in the surface boundary layers. At greater heights (e.g., $>150 \mathrm{~m})$ and in stable stratifications, the behavior of fluctuating shears is not yet known. The normal distribution gives a useful lower bound on shear probabilities, but seriously underestimates the likelihood of large shear values.

A simple model relating $\sigma_{\Delta u}$ to the correlation coefficient between velocity fluctuations at two levels is also presented. 


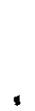




\section{CONTENTS}

SUMMARY................................. $i$...

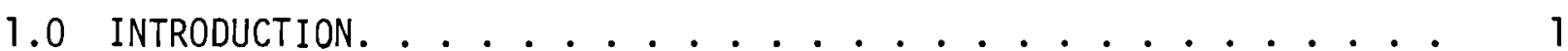

2.0 SUMMARY OF SOME PREVIOUS WORK . . . . . . . . . . 3

3.0 RESULTS ............................ 5

3.1 DATA COLLECTION. ................. 5

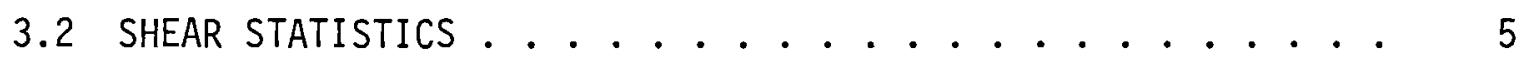

3.3 COMPARISON WITH FICHTL AND RAMSDELL FORMULAS . . . . . . 8

3.4 EFFECTS OF AVERAGING TIMES .................... 11

3.5 PROBABILITIES OF EXTREME EVENTS. . . . . . . . . . . 14

4.0 A SIMPLE THEORY . . . . . . . . . . . . . . . . 23

5.0 CONCLUSIONS . . . . . . . . . . . . . . . . 27

6.0 REFERENCES. . . . . . . . . . . . . . . . . 29 


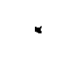




\section{FIGURES}

1 Schematic Diagram of Anemometer Array. . . . . . . . . . 6

2 Total Velocity Shear Distribution. ............ 9

$3 \sigma_{\Delta u} / \Delta z$ as a Function of $\bar{U} / \Delta z$ from Equation (1) ....... 12

4 Measured $\sigma_{\Delta u} / \Delta z$ as a Function of $\bar{U} / \Delta z \ldots \ldots 13$

$5 \quad \sigma_{\tau} / \sigma_{\tau=0.2}$ as a Function of $\tau \ldots \ldots 15$

$6 \sigma_{\Delta u} / \Delta \bar{U}$ as a Function of $\Delta z / \bar{z}$ from Equation (1), $L_{0}=-100 \mathrm{~m} . \ldots 18$

$7 \sigma_{\Delta u} / \Delta \bar{U}$ as a Function of $\Delta z / \bar{z}$ from Equation (1), $1_{0}=-500 \mathrm{~m} . . .19$

8 Probability of Total Velocity Difference Exceeding Indicated Values; $\bar{U}=12 \mathrm{~m} / \mathrm{s}, \sigma_{\Delta u}=1.5 \mathrm{~m} / \mathrm{s} . \ldots . . . . . .20$

9 Probability of Normalized Shear Exceeding a Specified Value. . . 21

\section{$\underline{\text { TABLES }}$}

1 Summary of Wind Shear Statistics ............. 7

2 Least Squares Fits to $\sigma_{\Delta u} / \Delta z=C(\bar{U} / \Delta z)^{n}$ Using Equation (1) ... 10

$3 \sigma_{\Delta u} / \Delta \bar{U}$ Statistics for Five Sets of Measurements. ...... 16

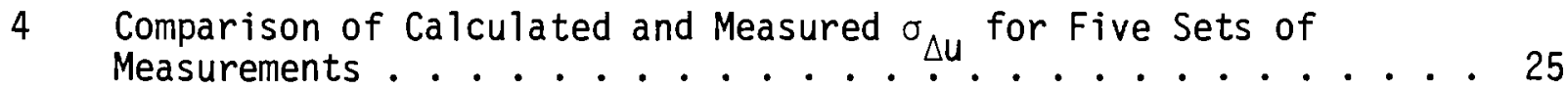

5 Comparison of Calculated and Measured $\sigma_{\Delta u}$ for Ramsdell's 26 


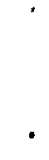




\subsection{INTRODUCTION}

Wind shears, particularly those along the vertical direction, may be an important factor in the response of a wind turbine to the ambient wind field and in the structural fatigue experienced by such machines. The mean wind shear is relatively well understood in sites with smooth, homogeneous upwind fetch, and can be described in terms of similarity theory, at least in the surface boundary layer (cf. Panofsky, 1977, for a review of current theories). In more complex terrain the mean shear structure may be altered drastically, and theoretical descriptions are far less satisfactory.

There are several complicating factors that may exist even in the simple terrain cases. One is the presence of nocturnal jets that arise as a result of the decoupling of elevated layers of the atmosphere from a relatively shallow surface layer. Under such circumstances quite large values of mean shear may persist for some time and wind speeds at, for example, $100 \mathrm{~m}$ height may be substantial while surface conditions are virtually calm (Sisterson and Frenzen, 1978).

A second factor of importance, and the one with which this report is concerned, is the fluctuating aspect of wind shears in the vertical direction. These fluctuating wind components may easily produce short-lived shears that are two or more times larger than the mean values. They may thus provide a critical source of added fluctuating loads to wind turbines exposed to them.

There are four principal objectives of the present study. The first is to provide detailed statistics on wind shear for a few selected cases of moderately strong winds. The second is to compare various aspects of these cases with the results obtained from several earlier studies, viz., those of Fichtl (1971, 1972) and Ramsdel1 (1978), and to resolve some apparent discrepancies in the results. The third is to examine aspects of the probability distribution for the occurrence of "extreme" shears. The last is to study the effects of averaging times on the wind shear distributions in order to relate "instantaneous" shear measurements to quantities of importance for an actual wind turbine. 
It is important to realize that the results of this study apply only to wind characteristics over level, homogeneous terrain, in slightly unstable to neutral conditions. The behavior of the wind under other conditions may be substantially different. 


\subsection{SUMMARY OF SOME PREVIOUS WORK}

Ficht1 (1971, 1972) carried out an analysis of 11 sets of turbuience measurements, under unstable conditions, obtained from the NASA 150-m tower at Cape Kennedy. His principal findings may be summarized by a set of three equations, one each for the second, third and fourth moments of the distribution of the fluctuating shears. They are

$$
\begin{gathered}
\frac{\sigma_{\Delta u}}{u_{\star_{0}}}=\left[0.0669 \ln \left\{\left(\frac{0.345}{\xi}\right)^{4}+61^{4}\right\}+0.57-0.11 \ln \mu\right]\left(\frac{\eta}{0.001}\right)^{0.23} \\
K \equiv \frac{\mu_{4}}{\sigma_{\Delta u}}=3+1.87 \mathrm{e}^{-1.66 \Delta z / \bar{z}} \\
S k \equiv \frac{\mu_{3}}{\sigma_{\Delta u}}= \begin{cases}0.91 \mathrm{e}^{-1.66 \Delta z / \bar{z}} & -\bar{z} / L_{0} \leq 1 \\
=0.08 & -\bar{z} / L_{0}>1\end{cases}
\end{gathered}
$$

Here, $u_{\star_{0}}$ is the surface friction velocity, $L_{0}$ is the Monin-0bukhov length, $\Delta z$ is the height difference between two levels, i.e., $z_{2}-z_{1}, \bar{z}=$ $\left(z_{1}+z_{2}\right) / 2, n=f \Delta z / u_{\star_{0}}, \xi=f \bar{z} / u_{\star_{0}}$ and $\mu=-u_{\star_{0}} /\left(f L_{0}\right)$, where $f$ is the Coriolis parameter. $K$ is the kurtosis and $S k$ the skewness of the distribution, $\sigma_{\Delta u}$ is the standard deviation of the velocity differences between two levels, and $\mu_{3}$ and $\mu_{4}$ are the 3 rd and 4 th moments of the distribution, respectively.

In the limit of neutral stability, which we may assume occurs for high enough wind speeds, (1) fails since $\mu \rightarrow 0$. However, for comparison purposes we may select some arbitrary, large negative value for $L_{0}$, and thereby make some estimates of $\sigma_{\Delta u}$. It is also assumed that the elevation is low enough for the measurement points to remain in the surface boundary layer. This condition could be violated for some larger wind turbines. 
Ramsdel1 (1978) also analyzed vertical wind shears using a tower located downstream of much larger surface roughness elements. He found

$$
\frac{\sigma_{\Delta u}}{\Delta z}=0.22\left(\frac{\bar{U}(\bar{z})}{\Delta z}\right)^{0.90}
$$

where $\bar{U}(\bar{z})$ is the mean wind speed measured at $\bar{z}$. Both Fichtl and Ramsdell found a large degree of scatter in the skewness and kurtosis; for Ramsdell's data, Equations (2) and (3) were found to be acceptable.

Both authors also found that the probability distributions for shear were described by a Pearson Type IV curve (Elderton and Johnson 1969). Such a curve is approximately bell-shaped but skewed, and has an unlimited range. Fichtl found that the distribution tends toward a Gaussian (normal) curve, as $\Delta z / \bar{z} \rightarrow 2$.

A word on notation is in order here. Fichtl identifies $u$ as the longitudinal velocity component while Ramsdell defines $u$ with reference to his tower array. The angular differences between Ramsdell's u components and the longitudinal components of the wind are, with a single exception, less than $30^{\circ}$ for the data analyzed. For the current analysis, shears of wind speed were analyzed. Speeds are also designated by $u$ here, and the notation is, therefore, somewhat more in keeping with Fichtl's than Ramsdell's. values of $\bar{z}$ ranged between 9.8 and $36.5 \mathrm{~m}$ for Ramsdell's study and between 24 and $135 \mathrm{~m}$ for Fichtl's work. These differences are all relatively minor, however, and should not be a source of difficulty in comparisons. 


\subsection{RESULTS}

\subsection{DATA COLLECTION}

Data for this study were obtained from an array of towers equipped with three component Gi11 anemometers. The anemometers used are shown schematically in Figure 1; the towers were located in a region with roughness lengths varying between 0.02 and $0.11 \mathrm{~m}$, depending on wind direction. The fetch was reasonably uniform and flat for a distance of several kilometers. The data were digitized at a rate of $10 \mathrm{~Hz}$ and stored on magnetic tape. For the analyses, the data were then block-averaged in groups of 2 to 80 points, corresponding to averaging times of 0.2 to 8 seconds.

Data from five periods were analyzed; the mean wind speeds for the different runs varied between 11.2 and $18.3 \mathrm{~m} / \mathrm{s}$ at a height of $36.6 \mathrm{~m}$. Under these conditions, near-neutral stability may be assumed although slightly stable or unstable stratifications cannot be ruled out.

In order to simplify the study, the number of variables upon which the shear is known to depend was limited. The range of stabilities found in the data of Fichtl and Ramsdell was significantly reduced by limiting the study to periods of moderate to high wind speeds. In addition, only three combi-

nations of $\bar{z}$ and $\Delta z$ were used: $\Delta z=34.5 \mathrm{~m}$ with $\bar{z}=36.6 \mathrm{~m}, \Delta z=17.2 \mathrm{~m}$ with $\bar{z}=28 \mathrm{~m}$, and $\Delta z=17.2 \mathrm{~m}$, with $\bar{z}=45.2 \mathrm{~m}$. These combinations also allowed the use of up to three pairs of anemometers for each run and each combination of $\bar{z}$ and $\Delta z$. In practice, anemometer malfunctions or the loss of a propeller during strong winds occasionally made only two pairs available.

The minimum run duration was 2 hours, corresponding to 36,000 events of 0.2 second's duration and 900 of 8 seconds' duration.

\subsection{SHEAR STATISTICS}

Table 1 gives the measured mean shear, standard deviation, skewness, kurtosis, and mean wind speed at $\bar{z}$ at each tower for each of the five runs and for each of three pairs of $\Delta z$ and $\bar{z}$. The averaging time $\tau$ is 0.2 seconds in all cases. 


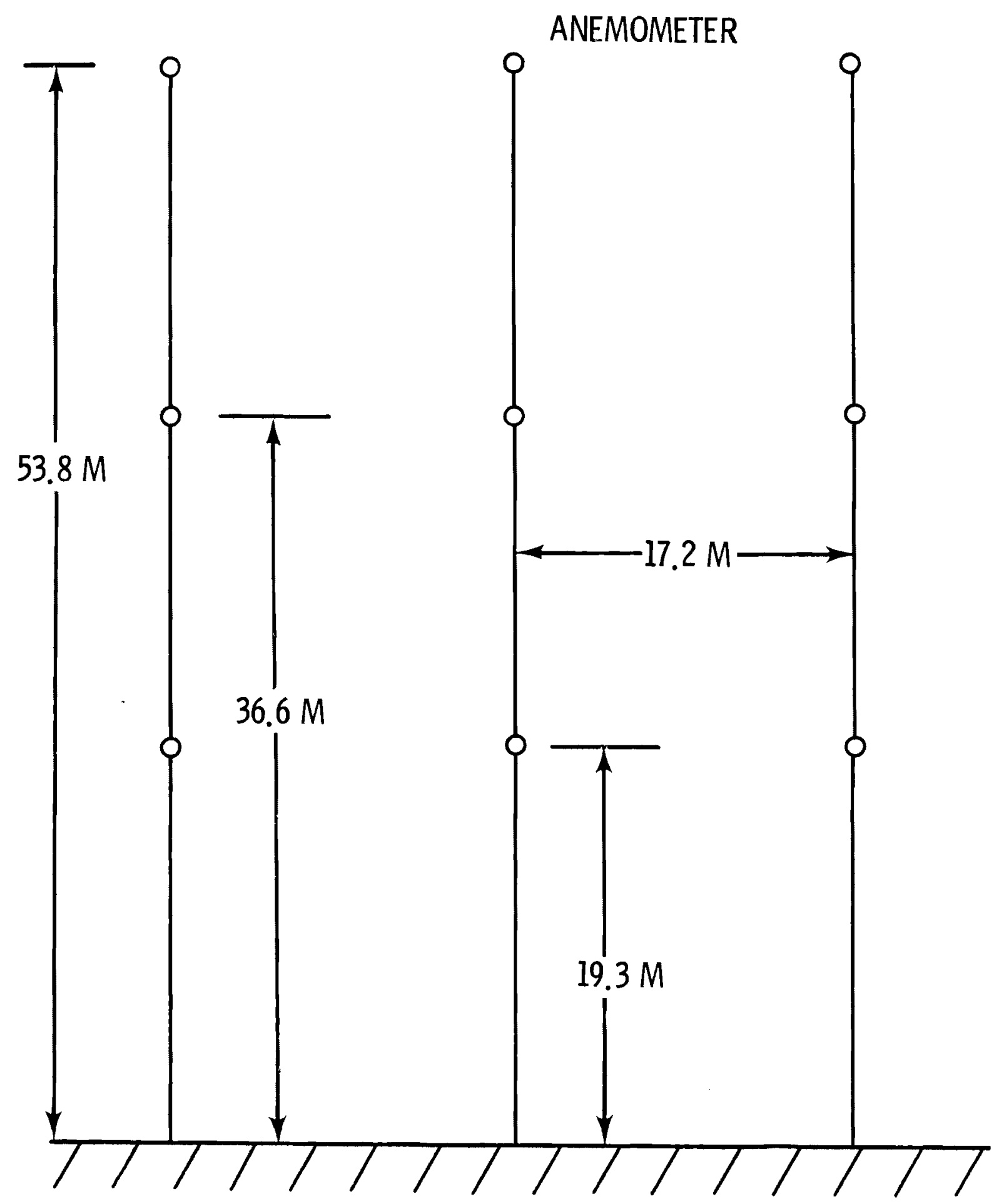

FIGURE 1. Schematic Diagram of Anemometer Array 
TABLE 1. Summary of Wind Shear Statistics

\begin{tabular}{|c|c|c|c|c|c|c|c|c|c|c|c|c|c|}
\hline \multirow[b]{2}{*}{ Run } & \multirow[b]{2}{*}{ Tower } & \multicolumn{4}{|c|}{$\bar{z}=36.6 \mathrm{~m}, \Delta z=34.5 \mathrm{~m}$} & \multicolumn{4}{|c|}{$\bar{z}=45.2 \mathrm{~m}, \Delta z=17.2 \mathrm{~m}$} & \multicolumn{4}{|c|}{$\bar{z}=28 \mathrm{~m}, \Delta z=17.2 \mathrm{~m}$} \\
\hline & & $\Delta \bar{U}$ & $\sigma_{\Delta u}$ & Sk & $k$ & $\Delta \bar{U}$ & ${ }^{\sigma} \Delta u$ & Sk & $K$ & $\Delta \bar{U}$ & $\underline{\sigma_{\Delta u}}$ & Sk & $K$ \\
\hline $5 / 8-5 / 9 / 79$ & 2 & 2.17 & 1.64 & 0.271 & 3.02 & 0.64 & 1.27 & 0.416 & 3.46 & 1.53 & 1.43 & 0.459 & 3.54 \\
\hline $21: 32-0: 02$ PST & 3 & 2.21 & 1.61 & 0.138 & 3.00 & - & - & - & - & - & - & - & - \\
\hline $\bar{U}_{36.6}=12.3 \mathrm{~m} / \mathrm{s}$ & 4 & 2.24 & 1.66 & 0.219 & 3.06 & 0.87 & 1.29 & 0.351 & 3.62 & 1.36 & 1.46 & 0.421 & 3.44 \\
\hline $5 / 8-5 / 9 / 79$ & 2 & 1.99 & 1.49 & 0.195 & 3.05 & 0.56 & 1.15 & 0.441 & 3.57 & 1.42 & 1.30 & 0.347 & 3.61 \\
\hline $0: 02-2: 02$ PST & 3 & 1.92 & 1.46 & 0.149 & 3.12 & - & - & - & - & - & - & - & - \\
\hline $\bar{U}_{36.6}=11.2 \mathrm{~m} / \mathrm{s}$ & 4 & 2.05 & 1.54 & 0.251 & 3.22 & 0.89 & 1.15 & 0.415 & 3.88 & 1.16 & 1.31 & 0.402 & 3.35 \\
\hline $12 / 10 / 79$ & 2 & 1.69 & 1.65 & 0.282 & 3.04 & - & - & - & - & - & - & - & - \\
\hline $11: 09-13: 09$ PST & 3 & 2.12 & 1.65 & 0.342 & 3.18 & 0.70 & 1.20 & 0.631 & 4.25 & 1.42 & 1.40 & 0.464 & 3.56 \\
\hline $\bar{U}_{36.6}=13.3 \mathrm{~m} / \mathrm{s}$ & 4 & 1.77 & 1.69 & 0.343 & 3.19 & 0.64 & 1.19 & 0.564 & 4.21 & 1.13 & 1.42 & 0.436 & 3.54 \\
\hline $3 / 14 / 80$ & 2 & 2.02 & 1.99 & 0.329 & 3.36 & 0.85 & 1.37 & 0.630 & 4.69 & 1.16 & 1.64 & 0.391 & 3.71 \\
\hline $10: 43-12: 43$ PST & 3 & 2.00 & 1.96 & 0.372 & 3.30 & 1.09 & 1.34 & 0.700 & 4.78 & 0.90 & 1.60 & 0.521 & 3.79 \\
\hline $\bar{U}_{36.6}=14.6 \mathrm{~m} / \mathrm{s}$ & 4 & 2.18 & 1.96 & 0.394 & 3.55 & 0.59 & 1.35 & 0.636 & 4.81 & 1.62 & 1.63 & 0.509 & 3.79 \\
\hline $12 / 14 / 80$ & 2 & 2.64 & 2.27 & 0.345 & 3.16 & 1.31 & 1.56 & 0.714 & 4.25 & 1.33 & 1.96 & 0.439 & 3.42 \\
\hline $11: 43-13: 43$ PST & 3 & - & - & - & - & 1.20 & 1.55 & 0.723 & 4.37 & - & - & - & - \\
\hline $\bar{U}_{36.6}=18.0 \mathrm{~m} / \mathrm{s}$ & 4 & 2.52 & 2.32 & 0.360 & 3.16 & 0.69 & 1.57 & 0.690 & 4.39 & 1.83 & 1.99 & 0.473 & 3.54 \\
\hline
\end{tabular}


For $\tau=0.2$ seconds, all but one of the probability distributions of vertical shear for $\Delta z=17.2 \mathrm{~m}$ were found to be Pearson type IV distributions; for $\Delta z=34.5 \mathrm{~m}$, however, out of 14 cases, 7 were type I, 2 were type VI and 5 were type IV. The differences between the three types in these cases are al1 smal1. The type VI and I distributions have limited ranges in one and two directions, respectively, but here all three types are bell-shaped and positively skewed. Moreover, the limits on the ranges are so large that, in practice, the limiting ranges of the shears are never realized and the limitations are therefore insignificant.

Averaging time had some effect on the types of distributions, but no we11-defined trends were discerned. Comparison of the results for $\tau=0.2$ and 8 seconds for $\Delta z=34.5 \mathrm{~m}$ showed that two type I and one type VI distributions for $\tau=0.2$ seconds became type IV distributions for $\tau=8$ seconds. In addition, one type VI changed to a type I, one type IV changed to a type VI, and one type IV changed to a type I. For $\Delta z=17.2 \mathrm{~m}$, and $\tau=8 \mathrm{sec}-$ onds, four type I and one type VI distributions were found. Again, the differences between types IV, I and VI should not be expected to drastically alter the shapes of the distribution curves.

An example of wind shear distribution is shown in Figure 2. A type IV curve derived from the data is drawn through the observed points; the fit is extremely good. A Gaussian fit derived from the mean shear and standard deviation is also shown for comparison. This type of approximation will be referred to again in Section 3.5 .

\subsection{COMPARISON WITH FICHTL AND RAMSDELL FORMULAS}

In deriving his formula (1) for $\sigma_{\Delta u}$, Fichtl (1971) systematically studied the dependence of this quantity on $\Delta z, \bar{z}$ and $u_{\star_{0}}$, using similarity theory as a guide to the choice of dimensionless variables needed to describe his results. Ramsdell approached the same problem from a more empirical standpoint, noting that $\sigma_{\Delta u} / \Delta z$ seemed to obey a power law with the independent variable $(\bar{U} / \Delta z)$. In effect, this approach lumps the dependence of $\sigma_{\Delta u}$ on $u_{\star_{0}}$ and $\bar{z}$ into a dependence on a single quantity, $\bar{U}(\bar{z})$. As a result, it might be 


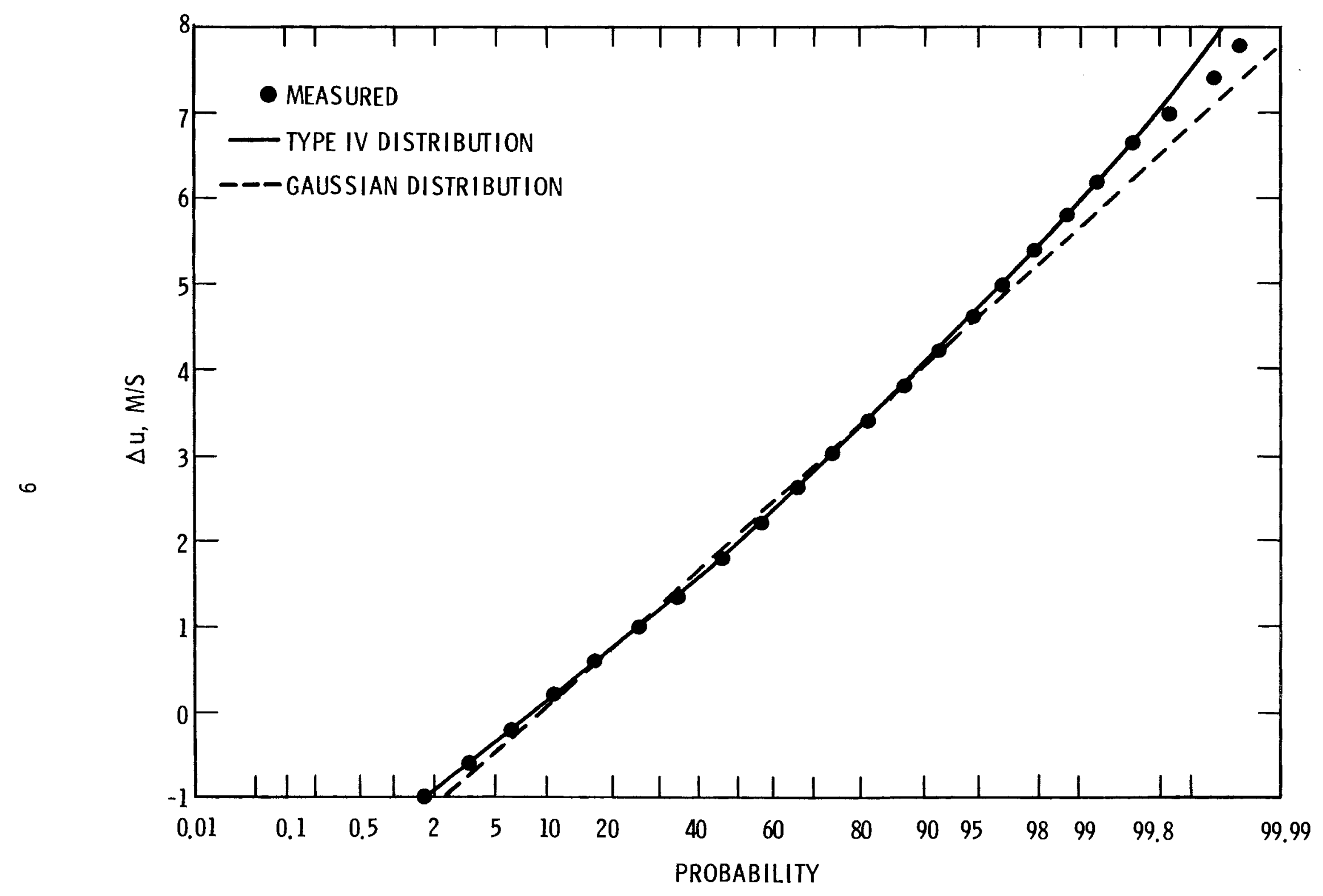

FIGURE 2. Total Velocity Shear Distribution 
anticipated that such an approach would be valid for a given data set but might be harder to generalize for other conditions. The Ramsdell formula should, however, be obtainable from Fichtl's formula if the two approaches are compatible. It is easy to show that this is the case, and this is done below.

A series of values of $\sigma_{\Delta u}$ were generated from (1) using a value of $L=-100 \mathrm{~m}$. The value of $\bar{z}$ ranged from 10 to $100 \mathrm{~m}$. In practice, a value of $100 \mathrm{~m}$ may be too large since it could well be out of the surface boundary layer. Least squares power fits of the form $\sigma_{\Delta u} / \Delta z=C(\bar{U} / \Delta z)^{n}$ were generated for values of $z_{0}$ in the range 0.05 to $1.6 \mathrm{~m}$. For each value of $z_{0}$, a range of $u_{\star_{0}}$ was selected such that the resulting values of $\bar{U} / \Delta z$ lay in the approximate interval $0.06-1.5 \mathrm{~s}^{-1}$. (Ramsde11's range of $\bar{U} / \Delta z$ values was 0.13 1.55.) Some of the calculations were repeated with $L=-500 \mathrm{~m}$. Table 2 shows the results.

\begin{tabular}{|c|c|c|c|}
\hline & $\underline{z}_{0}(\mathrm{~m})$ & $C$ & $n$ \\
\hline$L_{0}=-100$ & $\begin{array}{l}0.05 \\
0.10 \\
0.20 \\
0.40 \\
0.80 \\
1.6\end{array}$ & $\begin{array}{l}0.11 \\
0.12 \\
0.14 \\
0.16 \\
0.20 \\
0.26\end{array}$ & $\begin{array}{l}0.86 \\
0.88 \\
0.90 \\
0.90 \\
0.92 \\
0.93\end{array}$ \\
\hline$L_{0}=-500$ & $\begin{array}{l}0.05 \\
0.40 \\
1.6\end{array}$ & $\begin{array}{l}0.11 \\
0.16 \\
0.23\end{array}$ & $\begin{array}{l}0.86 \\
0.90 \\
0.93\end{array}$ \\
\hline
\end{tabular}

Ramsdell estimated his roughness length to be approximately $1 \mathrm{~m}$. His values of $C=0.22$ and $n=0.90$ are in excellent agreement with the values derived from Fichtl's formula and given in Table 2.

The difficulty in using results such as those presented in Table 2 is that the values of $C$ and $n$ depend upon the particular range of $\bar{U} / \Delta z$ values used and the combination of $u_{*_{0}}, \Delta z$ and $\bar{z}$ that generated these values. 
This can be seen in Figure 3, where Fichtl's formula has been used to generate $\sigma_{\Delta u} / \Delta z$ values for the range of $\bar{U}, \Delta z$ and $\bar{z}$ used for the current measurements and summarized in Table 1. The points divide into two groups, falling along two distinct lines. All the points on the lower line arise from the $\bar{z}=45.2 \mathrm{~m}$ and $\Delta z=17.2 \mathrm{~m}$ values; the points on the upper 1 ine result from using $\bar{z}=36.6 \mathrm{~m}$ with $\Delta z=34.5 \mathrm{~m}$ and $\bar{z}=28 \mathrm{~m}$ with $\Delta z=17.2 \mathrm{~m}$. Similar results from the experimental data are shown in Figure 4 ; here, the data denoted by circles are found for $\bar{z}=45.2 \mathrm{~m}$ and $\Delta z=17.2 \mathrm{~m}$.

If a value of $L_{0}=-100 \mathrm{~m}$ is assumed, and if $u_{*_{0}}$ is adjusted to give the measured value of $\bar{U}(\bar{z})$ for each of the cases given in Table 1 , the results of the present set of measurements can be compared with Fichtl's formula (1). The ratio of measured to computed $\sigma_{\Delta u}$ is $1.00 \pm 0.10$, which shows excellent agreement between Fichtl's measurements and these. Changing $L_{0}$ to $-500 \mathrm{~m}$ has little effect on this result (ratio $=1.04 \pm 0.10$ ).

Ramsdell's empirical formula and power laws of this type may thus give useful estimates of $\sigma_{\Delta u}$ variations for a specified range of $\bar{U} / \Delta z$ values. However, in general it is recommended that Fichtl's formulation be used since it appears to provide greater generality and is still easy to evaluate. In terrain where roughness length changes significantly over a distance upwind less than 100 times the highest point of measurement, or where the terrain is complex in nature (e.g., ridges, forests, hills, ravines, etc.), neither approach should be expected to be very accurate. Moreover, under stable conditions these approaches are also likely to break down.

\subsection{EFFECTS OF AVERAGING TIMES}

Since the blades of a wind turbine require a finite time to complete a revolution, a large value of "instantaneous" wind shear may not be particularly significant. If a large wind shear persists for an entire revolution, however, it is more likely to have an effect on the machine. For this reason, we have calculated the shear statistics for a range of averaging times. The shorter averaging times would apply for smaller, more rapidly rotating blades; the longer times are relevant for large machines with slower 


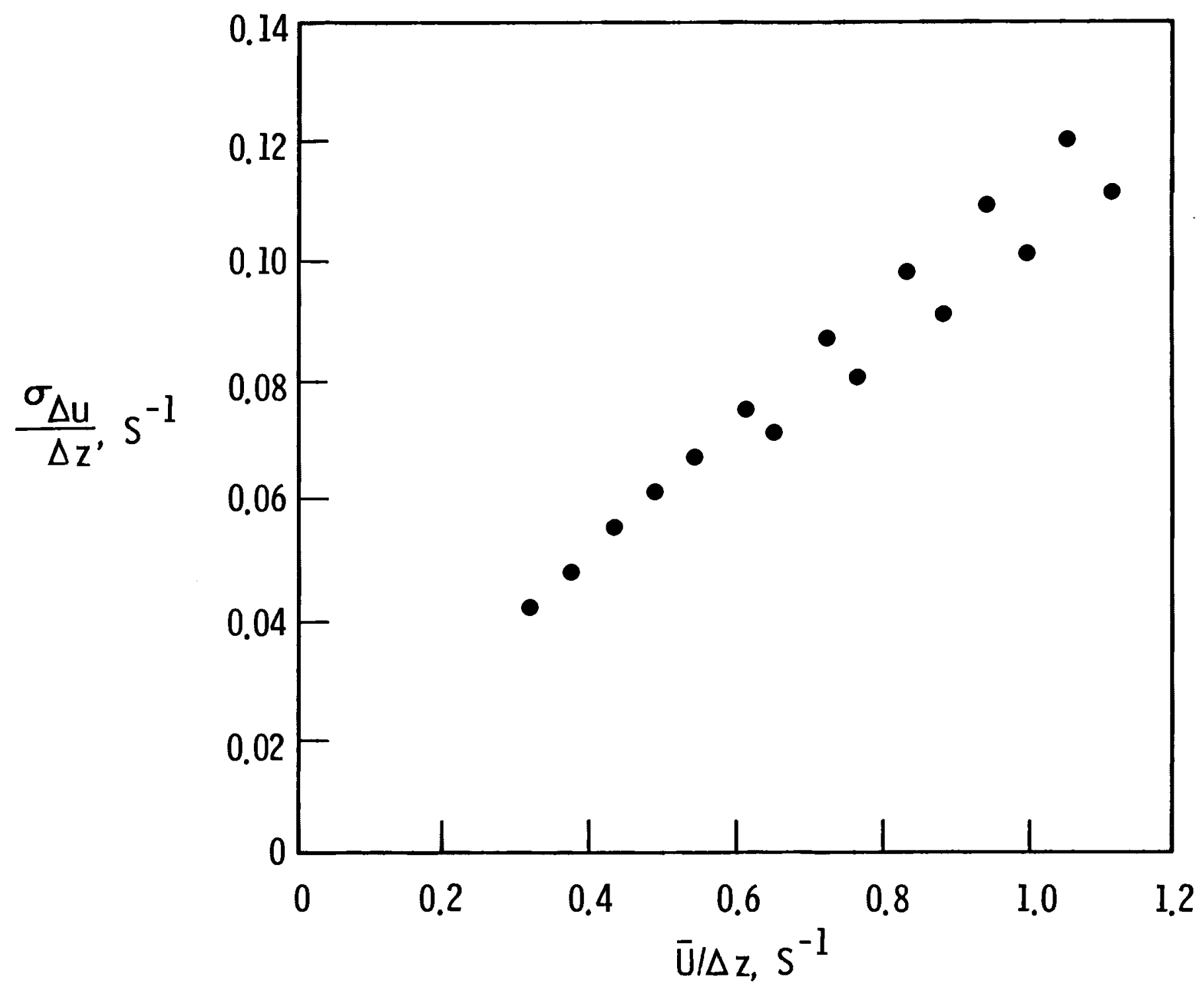

FIGURE 3. $\sigma_{\Delta u} / \Delta z$ as a Function of $\bar{U} / \Delta z$ from Equation (1). Lower set of points for $\Delta z=17.2 \mathrm{~m}, \bar{z}=45 \mathrm{~m}$ Upper set of points: $\Delta z=17.2 \mathrm{~m}, \bar{z}=78 \mathrm{~m}$ and $\Delta z=34.5 \mathrm{~m}, \bar{z}=36.6 \mathrm{~m}$ 


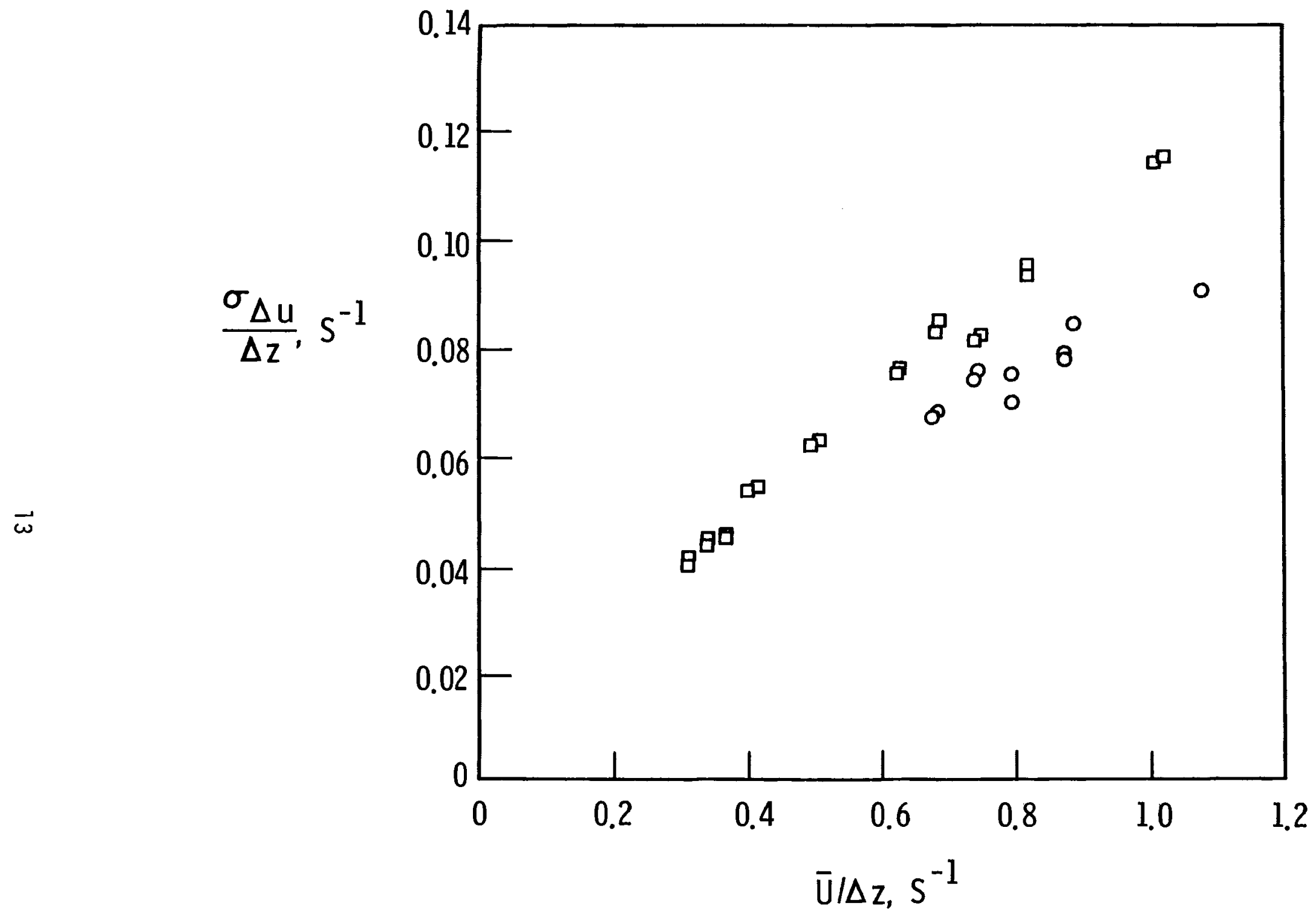

FIGURE 4. Measured $\sigma_{\Delta u^{\prime}} / \Delta z$ as a Function of $\bar{U} / \Delta z$. Circled points: $\Delta z=17.2 \mathrm{~m}, z=45 \mathrm{~m}$ 0thers: $\Delta z=34.5, \bar{z}=36.6$ and $\Delta z=17.2, \bar{z}=28$ 
rates of rotation. One might, for example, choose an averaging time equal to the time required for one revolution of a blade. The shear statistics can then be used to determine the number of revolutions per unit time that have a given range of shear values each of whose duration is one period of revolution.

As anticipated, the standard deviation of the fluctuating shear component, $\sigma_{\Delta u}$, decreases as the averaging time $\tau$ increases. Moreover, the rate of decrease appears to depend on $\Delta z$. Figure 5 shows this effect clearly. In the figure, $\sigma_{\tau} / \sigma_{\tau=0.2}$ is plotted as a function of $\tau$. The two curves correspond to $\Delta z$ values of $34.5 \mathrm{~m}$ and $17.2 \mathrm{~m}$; in the latter case the results for $\bar{z}=45.2 \mathrm{~m}$ and $\bar{z}=28 \mathrm{~m}$ are virtually identical. The 1 ines drawn through the data points correspond to least square fits of the form

$$
\sigma_{\tau} / \sigma_{\tau=0.2}=1.01-0.056 \tau+0.0026 \tau^{2} \quad \text { for } \Delta z=34.5 \mathrm{~m}
$$

and

$$
\sigma_{\tau} / \sigma_{\tau=0.2}=1.01-0.081 \tau+0.0042 \tau^{2} \quad \text { for } \Delta z=17.2 \mathrm{~m}
$$

An increase in $\tau$ from 0.2 seconds to 4 seconds thus can cause a reduction in $\sigma_{\Delta u}$ of almost $25 \%$. Hence, fluctuating shears measured by fast response wind sensors may substantially overestimate the severity of the environment to which a large machine is sensitive. Alternatively, shears determined from slow response instruments or time-averaged records may seriously underestimate the shear that it would experience.

\subsection{PROBABILITIES OF EXTREME EVENTS}

As seen from the example in Figure 2, a.Gaussian fit to the probability distribution for shears underestimates the probability of large magnitude shears. Nonetheless, between the $10 \%$ and $90 \%$ cumulative probability levels the Gaussian curve provides a rather good description of the data. Moreover, in a discussion of extreme events it serves as a useful lower bound for specifying certain properties of the distributions. 


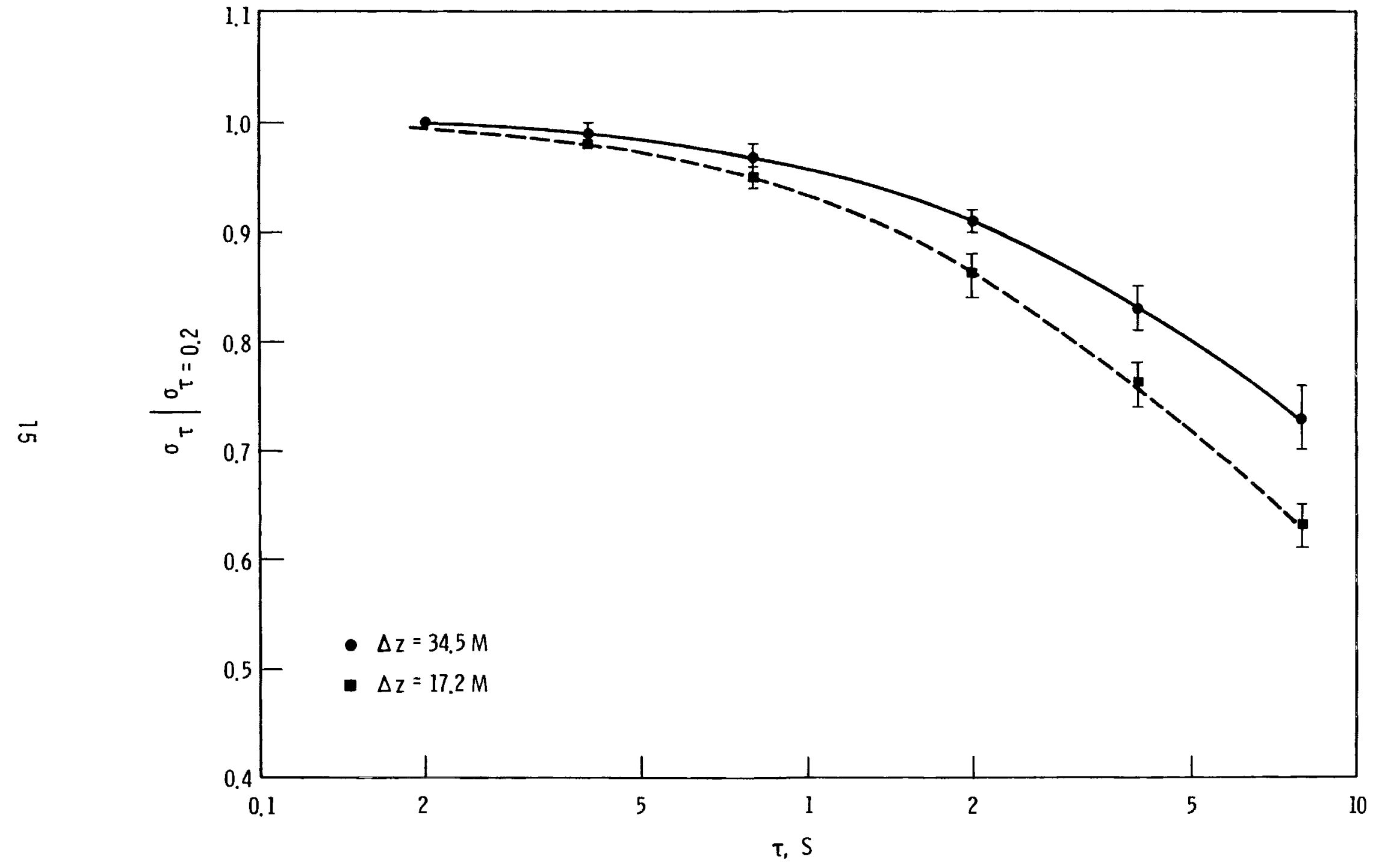

FIGURE 5. $\quad \sigma_{\tau} / \sigma_{\tau=0.2}$ as a Function of $\tau$ 
One can make a rough estimate of the probability of exceedance of certain shear values at any arbitrary instant by using $\sigma_{\Delta u}$ and an assumed normal distribution. Table 3 shows the ratios of $\sigma_{\Delta u}$ to $\Delta \bar{U}$ for $\tau=0.2 \mathrm{sec}-$ onds. This ratio is useful as it provides a measure of the importance of the fluctuating shear relative to the mean shear. The minimum value obtained is 0.73 . Hence, a fluctuating shear component that is twice the mean value amounts to a deviation from the mean of $1.37 \sigma_{\Delta u}$. This suggests that one may expect approximately $9 \%$ or more of al1 "instantaneous" shear values to be at least two times greater than the mean value for a separation of $34.5 \mathrm{~m}$. In many cases $\sigma_{\Delta u} / \Delta \bar{U}$ is considerably higher, and large values of shear will be even more likely.

TABLE 3. $\sigma_{\Delta u} / \Delta \bar{U}$ Statistics for Five Sets of Measurements

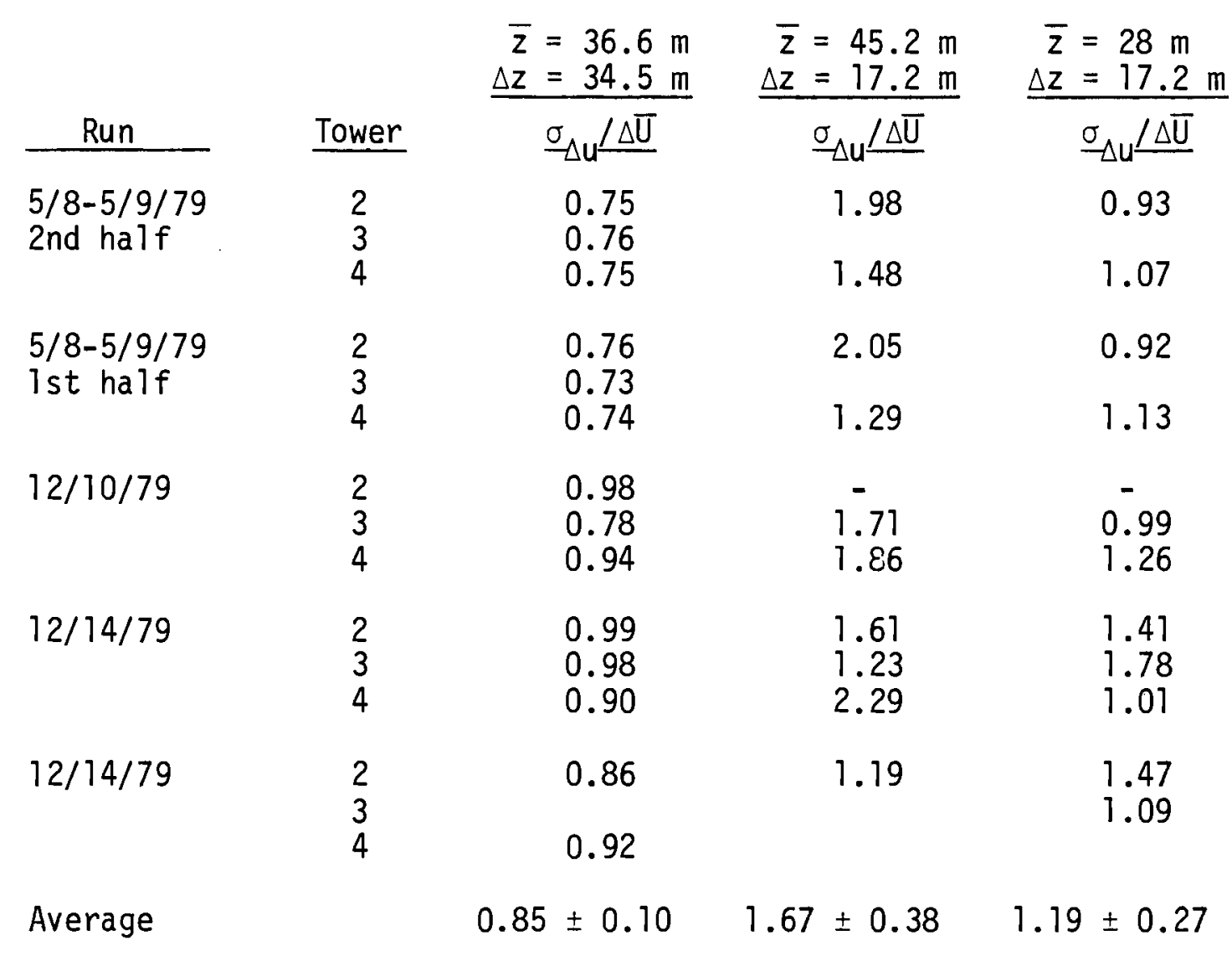


Figures 6 and 7 show values of $\sigma_{\Delta u} / \Delta \bar{U}$ as a function of $\Delta z / \bar{z}$ calculated from Equation (1) for two values of $L_{0}$. Also shown in Figure 7 are the average values of the data summarized in Table 3 for each of the $\Delta z$ and $\bar{z}$ combinations. The agreement is reasonably good except for the smallest values of $\Delta z / \bar{z}$, where the measured values of $\sigma_{\Delta u} / \Delta \bar{U}$ are considerably smaller than the calculated ones. The discrepancy apparently arises from measured values of $\Delta \bar{U}$ that are larger than the calculated ones. For large $\bar{z}$ and smal1 $\Delta \mathbf{z}, \Delta \bar{U}$ is relatively sma11, and errors in calculated values of $\Delta \bar{U}$ are therefore relatively more important. In any event, it is evident that $\sigma_{\Delta u}$ can easily be significantly larger than $\Delta \bar{U}$, and that, for fixed $\Delta z$, as the hub height of a wind turbine increases, $\sigma_{\Delta u} / \Delta \bar{U}$ will increase as well. The importance of the fluctuating shear component therefore increases as the hub height of the machine increases. Shears two or three times the mean shear values may thus be relatively common, even if the averaging time for the evaluation of the shears is one or more seconds.

Examination of the data obtained from the measurements described here reveals no obvious trends of skewness and kurtosis with averaging time. For example, for $\Delta z=34.5 \mathrm{~m}$ and $\bar{z}=36.6 \mathrm{~m}$, the averaged measured values of skewness and kurtosis were $0.29 \pm 0.08$ and $3.17 \pm 0.14$, respective1y, for $\tau=0.2$ seconds. Considering the scatter in the data, these values are in fair agreement with those given by Equations (2) and (3). For $\tau=8$ seconds, the corresponding values were $0.30 \pm 0.06$ and $3.09 \pm 0.14$. If we assume these values are actualiy constant within the experimental error, the dependence of the probability distribution of fluctuating vertical shears on averaging times may be determined from the behavior of $\sigma_{\Delta u}$ alone.

The nature of this dependence can be seen from the following example. Assume $\bar{z}=36.6 \mathrm{~m}, \Delta z=34.5 \mathrm{~m}, \bar{U}(\bar{z})=12 \mathrm{~m} / \mathrm{s}$ and $z_{0}=0.05 \mathrm{~m}$. From Figure 7 (for $L_{0}=-500 \mathrm{~m}$ ) we estimate that $\sigma_{\Delta u} / \Delta \bar{U} \sim 1$. If $\bar{U}(\bar{z})$ is $12 \mathrm{~m} / \mathrm{s}$, one can show from known micrometeorological wind profiles that $\Delta \overline{\mathrm{U}} \sim 1.5 \mathrm{~m} / \mathrm{s}$ so that $\sigma_{\Delta u}$ is also approximately equal to $1.5 \mathrm{~m} / \mathrm{s}$. If the skewness is 0.29 and the kurtosis is 3.17 , the probability distribution for the fluctuating shears is a Pearson type IV. Figure 8 shows the probability of exceeding various total velocity differences, under the above conditions, as a function 


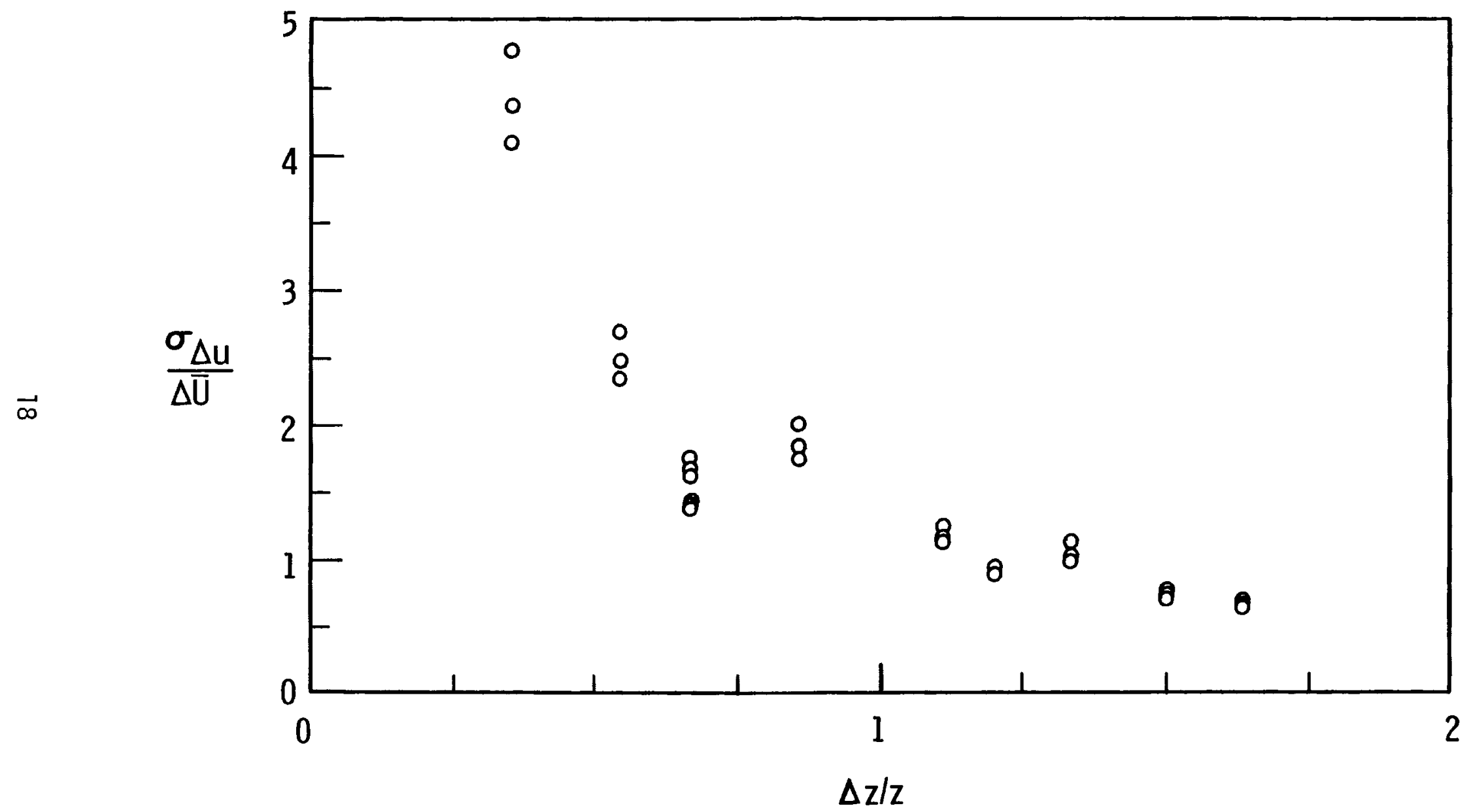

FIGURE 6. $\sigma_{\Delta u} / \Delta \bar{U}$ as a Function of $\Delta z / \bar{z}$ from Equation $(1), L_{0}=-100 \mathrm{~m}$ 


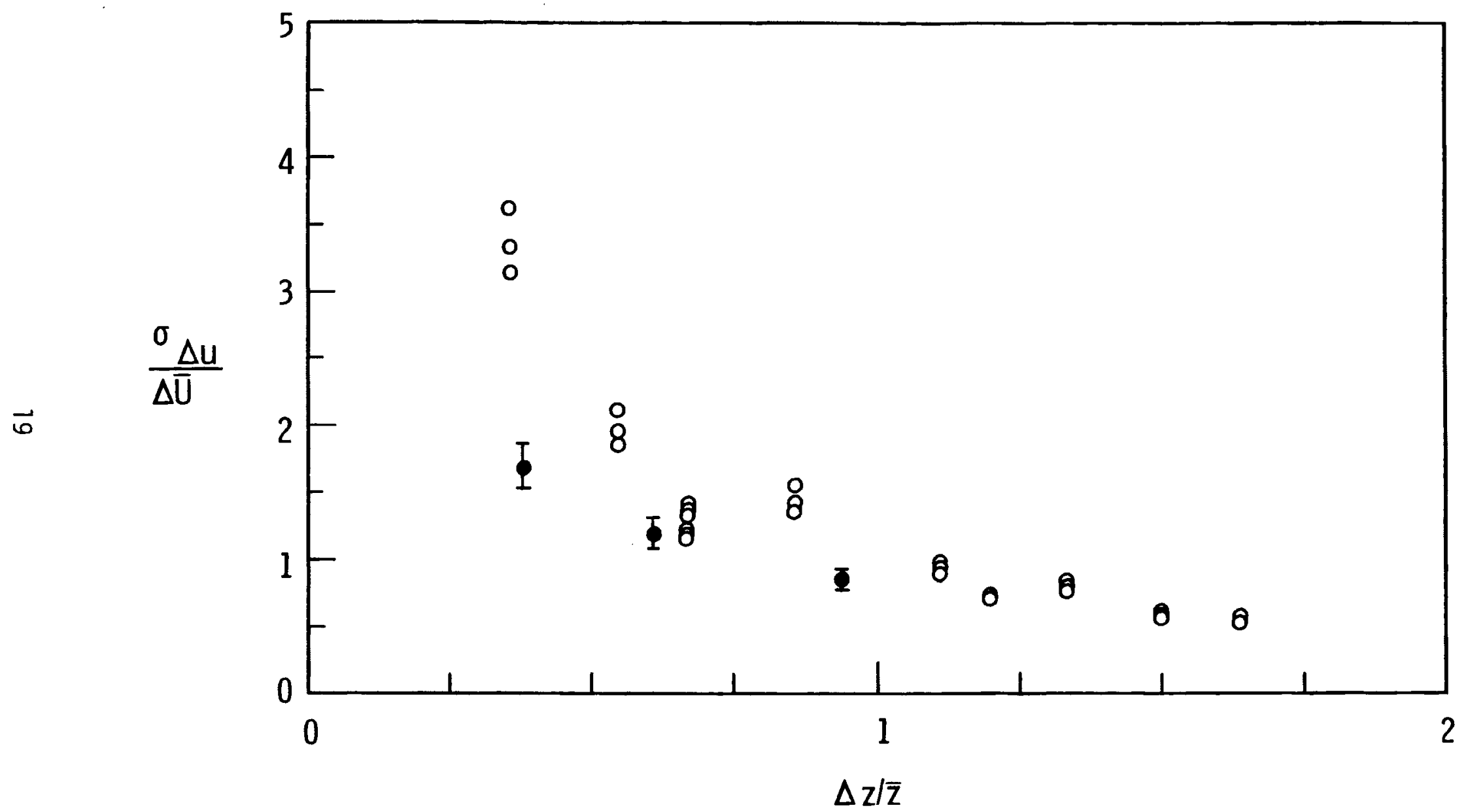

FIGURE 7. $\sigma_{\Delta u} / \Delta \bar{U}$ as a Function of $\Delta z / \bar{z}$ from Equation $(1), L_{0}=-500 \mathrm{~m}$ 


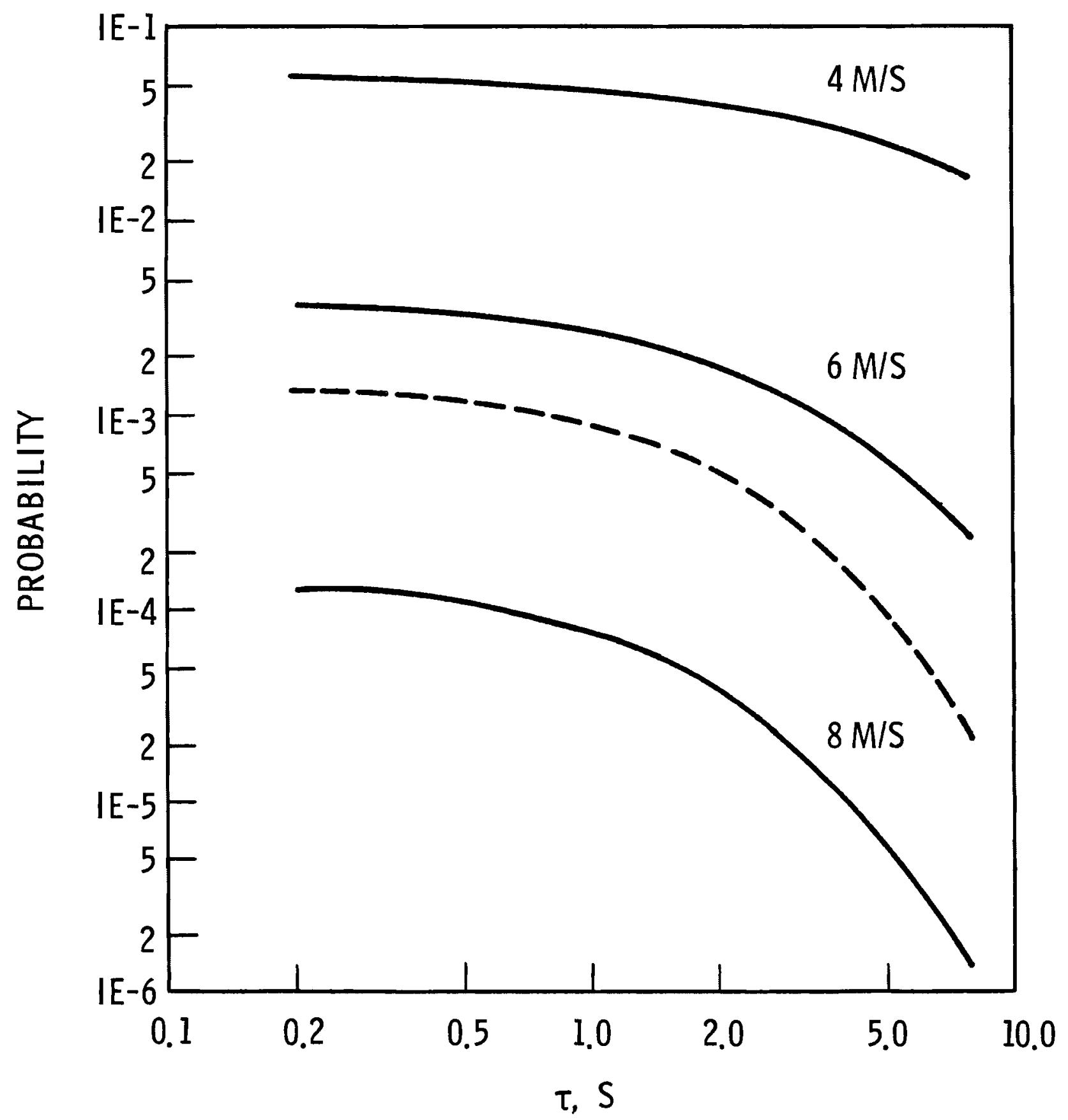

FIGURE 8. Probability of Total Velocity Difference Exceeding Indicated Values; $\bar{U}=12 \mathrm{~m} / \mathrm{s}, \sigma_{\Delta u}=1.5 \mathrm{~m} / \mathrm{s}$. Dashed line is Gaussian approximation. 
of averaging time. For comparison purposes, the Gaussian approximation to the case with a total shear of $6 \mathrm{~m} / \mathrm{s}$ is included. Such an approximation clearly underestimates the likelihood of larger shears, and the relative discrepancy increases as the magnitude of the shear increases.

Since the kurtosis and skewness are functions of $\Delta z / \bar{z}$, the probability of exceeding a given shear value is also a function of this ratio. If a Pearson Type IV distribution is assumed, and if the difference between the mean and instantaneous shear is normalized by $\sigma_{\Delta u}$, the probability of realizing a shear less than a specified value can be computed. Figure 9 shows the results. The curve labeled $\Delta z / \bar{z}=2$ has approximately the same behavior that would be computed if the probability distribution were Gaussian. The deviations from this curve for smaller values of $\Delta z / \bar{z}$ are apparent.

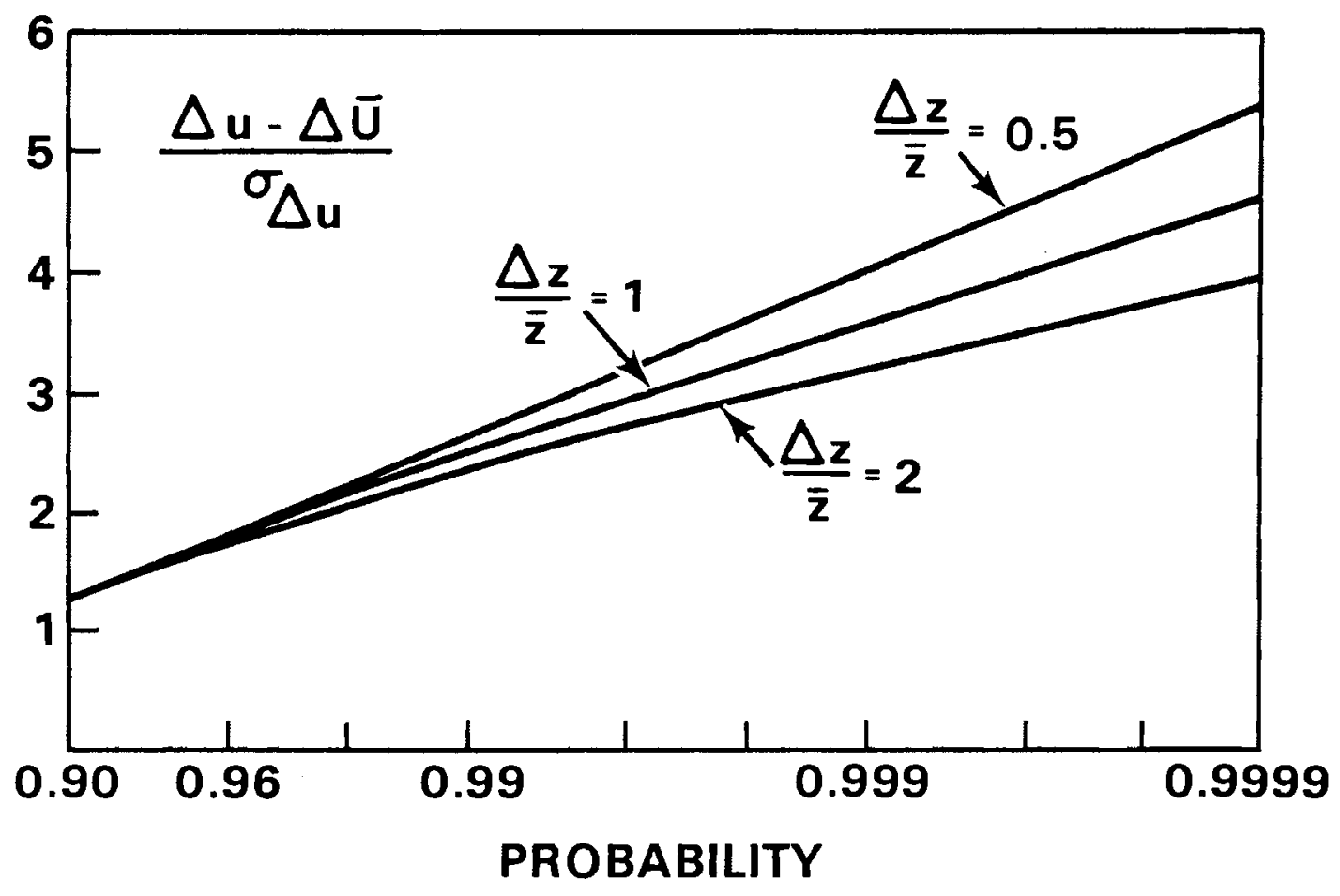

FIGURE 9. Probability of Normalized Shear Exceeding a Specified Value 
*

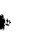

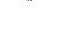




\subsection{A SIMPLE THEORY}

Fichtl and Ramsdell have both provided empirical formulas for the prediction of $\sigma_{\Delta u}$. Another approach is described below; while it is not necessarily any more accurate than either of the first two, it is instructive in relating $\sigma_{\Delta u}$ to other turbulence characteristics.

Ficht1 has shown that the joint probability distribution for velocities at two levels is not Gaussian. However, it has also been shown that the Gaussian approximation is acceptable if large excursions (e.g., $\gtrsim 1.5 \sigma_{\Delta u}$ ) from the mean are avoided. Hence, let us assume we can use the Gaussian approximation to get an estimate of $\sigma_{\Delta u}$ and compare the results of this assumption with the data.

For wind speeds $u_{1}$ and $u_{2}$ at two levels, the joint probability density is

$$
p\left(u_{1}, u_{2}\right)=\frac{\exp \left\{\left[\frac{-1}{2\left(1-\rho^{2}\right)}\right]\left[\left(\frac{u_{1}-\bar{u}_{1}}{\sigma_{1}}\right)^{2}-2 p\left(\frac{u_{1}-\bar{u}_{1}}{\sigma_{1}}\right)\left(\frac{u_{2}-\bar{u}_{2}}{\sigma_{2}}\right)+\left(\frac{u_{2}-\bar{u}_{2}}{\sigma_{2}}\right)^{2}\right]\right\}}{2 \pi \sigma_{1} \sigma_{2} \sqrt{1-\rho^{2}}}
$$

where $\bar{U}_{1}$ and $\bar{U}_{2}$ are the mean wind speeds at the two levels, $\rho$ is the correlation coefficient between the velocities at the two levels and $\sigma_{1}$ and $\sigma_{2}$ are the standard deviations of $u_{1}$ and $u_{2}$, respectively.

We are interested in cases where $u_{1}$ and $u_{2}$ differ by some amount. Let

$$
s=u_{2}-u_{1}
$$

Then the probability density function for $s$ is just

$$
p(s)=\int_{-\infty}^{\infty} p\left(u_{1}, u_{1}+s\right) d u_{1}
$$


It can be shown that this last expression becomes

$$
p(s)=\left[2 \pi\left(\sigma_{1}^{2}+\sigma_{2}^{2}-2 \rho \sigma_{1} \sigma_{2}\right)\right]^{-1 / 2} \exp \left\{\frac{-\left[s-\left(\bar{U}_{2}-\bar{U}_{1}\right)\right]^{2}}{2\left[\sigma_{1}^{2}+\sigma_{2}^{2}-2 \rho \sigma_{1} \sigma_{2}\right]}\right\} .
$$

This can be written in the form

$$
p(s)=\left[2 \pi \sigma_{\Delta u}{ }^{2}\right]^{-1 / 2} \exp \left\{\frac{-(\Delta u-\Delta \bar{U})^{2}}{2 \sigma_{\Delta u}{ }^{2}}\right\}
$$

i.e., the usual normal curve, where

$$
\sigma_{\Delta u}=\left(\sigma_{1}^{2}+\sigma_{2}^{2}-2 \rho \sigma_{1} \sigma_{2}\right)^{1 / 2}
$$

In neutral conditions in the surface boundary layer, $\sigma_{1} \sim \sigma_{2}=\sigma$ so that

$$
\sigma_{\Delta u} \sim \sqrt{2} \sigma(1-\rho)^{1 / 2}
$$

If $\rho$ is known, it can be substituted in the above expression to determine the ratio of $\sigma_{\Delta u}$ to $\sigma$. If $\rho$ is not known, it can be estimated from formulas (14-16) (Pielke and Panofsky, 1970)

$$
\rho(\Delta t, \Delta z)=\int_{-\infty}^{\infty}[F(n, z) F(n, z+\Delta z) \operatorname{coh}(n, \Delta z)]^{1 / 2} \cos [2 \pi n \Delta t-\phi(n, z)] d n
$$

Here, $F$ is the normalized power spectrum, $\phi$ is the phase function, $\operatorname{coh}(n, \Delta z)$ is the coherence and $\Delta t$ is the time lag between two measurements.

Two tests of this approach have been carried out. In the first, some data from this study were used. $\rho$ was not measured, so Equation (14) was used to estimate it. The coherence was assumed to have the form 


$$
\operatorname{coh}(n, \Delta z)=\exp \left\{\frac{-16 n \Delta z}{\bar{U}}\right\}
$$

and

$$
\phi=2 \pi n\left(\frac{\Delta z}{\bar{U}}\right)
$$

F was assumed to have the form proposed by Kaimal (1973) for the u spectrum (cf. Frost et a1. 1978).

$$
n F(n, z)=\frac{11.4 n z / \bar{U}}{1+192\left(\frac{n z}{\bar{U}}\right)^{5 / 3}}
$$

For $\Delta z=36.6 \mathrm{~m}$, $\rho$ was found to be $\sim 0.43$, essentially independent of $\bar{U}$. Hence,

$$
\sigma_{\Delta u} \sim 1.07 \sigma \quad
$$

Average values for all three towers were taken, for $\tau=0.2$ seconds. The

\begin{tabular}{|c|c|c|c|}
\hline Run & $\sigma$ & $1.07 \sigma$ & $\sigma_{\Delta \mathrm{u}}$ Meas \\
\hline $\begin{array}{l}5 / 8-5 / 9 / 79 \\
\text { (Period 2) }\end{array}$ & 1.37 & 1.47 & 1.50 \\
\hline $\begin{array}{l}5 / 8-5 / 9 / 79 \\
\text { (Period 1) }\end{array}$ & 1.58 & 1.69 & 1.64 \\
\hline $12 / 10 / 79$ & 1.67 & 1.79 & 1.66 \\
\hline $3 / 14 / 80$ & 2.09 & 2.24 & 1.97 \\
\hline $12 / 14 / 79$ & 2.34 & 2.50 & 2.30 \\
\hline
\end{tabular}
results are shown in Table 4 .

TABLE 4. Comparison of Calculated and Measured $\sigma_{\Delta u}$ for Five Sets of Measurements

$\sigma$ was evaluated from an anemometer located at $\bar{z}$. The agreement between $\sigma_{\Delta u}$ and $1.07 \sigma$ is seen to be reasonably good (ratio of measured to predicted $\sigma_{\Delta u}$ is $\left.0.94 \pm 0.05\right)$ especially in view of the many approximations that have been made. 
In a second case, comparisons have been made with one of the runs made by Ramsde11, test 11-11. In this test, the prevailing wind direction was predominantly along the $u$ direction of the anemometer array. Covariances between these components were evaluated by Ramsdell and can therefore be used to estimate $\rho$ for the wind speed. The following results were obtained.

TABLE 5. Comparison of Calculated and Measured $\sigma_{\Delta u}$ for Ramsde11's Test 11-11

\begin{tabular}{|c|c|c|c|c|}
\hline $\bar{z}$ & $\Delta z$ & $\stackrel{\rho}{\perp}$ & $\sqrt{2(1-\rho)} \sigma$ & $\sigma_{\Delta u}$ Meas. \\
\hline 9.75 & 5.7 & 0.63 & 1.05 & 1.03 \\
\hline 18.7 & 12.2 & 0.50 & 1.22 & 1.34 \\
\hline 15.85 & 17.9 & 0.31 & 1.43 & 1.43 \\
\hline 36.5 & 23.4 & 0.34 & 1.40 & 1.45 \\
\hline 30.4 & 35.6 & 0.12 & 1.62 & 1.60 \\
\hline 27.55 & 41.3 & 0.09 & 1.65 & 1.61 \\
\hline
\end{tabular}

$\sigma$ was determined from the average value of $\sigma_{u}$ at heights of $6.9,12.6$, 24.8 and $48.2 \mathrm{~m}$, and has the value $\sigma_{u}=1.22 \pm 0.05$. This value was used for all heights, and was used in (13) to calculate $\sigma_{\Delta u}$. The agreement between measured and calculated $\sigma_{\Delta u}$ is extremely good (ratio of predicted to measured values is $0.99 \pm 0.04$ ) and lends further credibility to this simple theoretical approach. More extensive testing is required, however, before it can be accepted with full confidence.

It should be noted that while the theory discussed here provides an alternate means of estimating $\sigma_{\Delta u}$, from an operational standpoint it may not be any easier to apply than equation (1). Here one needs values for $\bar{U}$ and $\sigma$, while (1) requires a knowledge of $u_{*}$. (Both assume $\Delta z$ and $\bar{z}$ are known.) A value of $u_{\star}$, together with $z_{0}$, allows one to determine $\bar{U}$ and $\sigma$ under neutral conditions, so the required input for the two approaches is comparable. This latter approach, however, is an example of the application of basic surface layer theory to the problem of fluctuating wind shears. 


\subsection{CONCLUSIONS}

A new series of wind shear measurements has been shown to be consistent with earlier work carried out by Fichtl (1971, 1972). In addition, an alternate method of describing $\sigma_{\Delta u}$, proposed by Ramsdell (1978), is compatible with the more generic formulation given by Fichtl.

The effects of averaging time on the first four moments of the probability distribution function for wind shear fluctuations have been determined. Only the second moment seems to be affected, and equations for the variation of $\sigma_{\Delta u}$ with averaging time $\tau$ have been determined for several $(\Delta z, \bar{z})$ combinations. Even for averaging times of one or more seconds, the probability of large fluctuating shears was shown to be appreciable, and shears two or more times greater than the mean shear are relatively common. 
. 


\subsection{REFERENCES}

Elderton, W. P. and N. L. Johnson. 1969. Systems of Frequency Curves. Cambridge University Press.

Ficht1, G. H. 1971. "Standard Deviation of Vertical Two-Point Longitudinal Velocity Differences in the Atmospheric Boundary Layer." BoundaryLayer Meteor., 2:137-151.

Fichtl, G. H. 1972. "Probability Distribution of Vertical Longitudinal Shear Fluctuations." J.Appl. Meteor., 9:51-63.

Kaimal, J.C. 1973. "Turbulence Spectra, Length Scales and Structure Parameters in the Stable Surface Layer." Boundary-Layer Meteor., $4: 289-309$.

Panofsky, H. A. 1977. "Wind Structure in Strong Winds Below $150 \mathrm{~m} . "$ Wind Eng., 1:91-103.

Pielke, R. A. and H. A. Panofsky. 1970. "Turbulence Characteristics Along Severa 1 Towers." Boundary-Layer Meteor., 1:115-130.

Ramsde11, J. V. 1978. "Wind Shear Fluctuations Downwind of Large Surface Roughness Elements." J. Appl. Meteor., 17:436-443.

Sisterson, D. L. and P. Frenzen. 1978. "Nocturnal Boundary Layer Wind Maxima and the Problem of Wind Power Assessment." Environmental Science and Technology, 12:218-221. 
No. of

Copies

OFFSITE

A.A. Churm

DOE Chicago Patent Group

9800 S. Cass Avenue

Argonne, IL 60439

C.I. Aspliden

Department of Energy

600 E Street, N.W.

Washington, DC 20545

G.P. Tennyson

Department of Energy

Albuquerque Operations Office

P.0. Box 5400

Albuquerque, NM 87115

27 DOE Technical Information Center

W. Frost

FWG Associates, Inc.

271A Lakewood Drive

Tullahoma, TN 37388

G. Ficht1

7703 Oakridge Drive

Huntsville, AL 35802

J.M. Kos

Hamilton Standard Div. of UTC

Bradley Field Road

Windsor Locks, CT 06096

Jean Mayhew

Mail Stop I-M-3

Hamilton Standard

Windsor Locks, CT 06096

M.A. Bowes

Kaman Aerospace Corporation

01d Windsor Road

Bloomfield, CT 06002
No. of

Copies

\section{OFFSITE}

T.R. Richards

NASA/LeRC

21000 Brookpark Road

Cleveland, $\mathrm{OH} 44135$

D. Spera

NASA/LeRC

21000 Brookpark Road

Cleveland, $\mathrm{OH} 44135$

J.C. Ka ima 1

NOAA/ERL/WPL

3000 Marine Street

Boulder, CO 80302

W. Holley

Department of Mechanical Engr. Oregon State University

Corvallis, OR 97331

A.C. Hansen

Rockwel 1 International

P. 0 . Box 464

Golden, C0 80401

E.G. Kadlec

Sandia Labs 4715

Box 5800

A1buquerque, NM 87165

R.H. Kirchhoff

Department of Mechanical Engr. University of Massachusetts

Amherst, MA 01003

A.B. Van Rennes

The Bendix Corporation

Executive Offices

Bendix Center

Southfield, MI 48037 
No. of

Copies

OFFSITE

F.S. Stoddard

U.S. Windpower Association

25 Adams Street

Burlington, MA 01803

R. Akins

Dept. of Engr. Sci. \& Mech.

Virginia P.I. and S.U.

Blacksburg, VA 24061

ONSITE

2 DOE Richland Operations Office

P.0. Box 550

Richland, WA 99352

H.E. Ransom

S. Smith

54 Pacific Northwest Laboratory

Battelle Boulevard

Richland, WA 99352

J.R. Connell

J.C. Doran (10)

R.L. Drake

C.E. Elderkin

V.K. Hopkins (15)

A.H. Miller

E.L. Owzarski

W.T. Pennell

D.C. Powe 1

J.V. Ramsde11

D.S. Renne

H.L. Wegley

L.L. Wende11

R.K. Woodruff

Technical Information Files (5)

Publishing Coordination (2) 